\begin{tabular}{|c|c|c|c|}
\hline \multirow{3}{*}{$\begin{array}{r}\text { Case Reports in } \\
\text { Gastroenterology }\end{array}$} & \multirow{2}{*}{\multicolumn{2}{|c|}{ Case Rep Gastroenterol 2016;10:50-56 }} & \multirow[b]{3}{*}{$\begin{array}{l}\text { Karger } \\
\text { Open access }\end{array}$} \\
\hline & & & \\
\hline & $\begin{array}{l}\text { DOI: } 10.1159 / 000444012 \\
\text { Publisnea onitne: TVlay 19, } 2016\end{array}$ & $\begin{array}{l}\text { (C) } 2016 \text { The Author(s) } \\
\text { Published by S. Karger AG, Basel } \\
\text { www.karger.com/crg }\end{array}$ & \\
\hline
\end{tabular}

\title{
Resected Hepatocellular Carcinoma in a Patient with Crohn's Disease on Azathioprine
}

\author{
Valérie Heron $^{a} \quad$ Kyle Joshua Fortinsky ${ }^{b} \quad$ Gillian Spiegle $^{b} \quad$ Nir Hilzenrat $^{c}$ \\ Andrew Szilagyi ${ }^{\mathrm{C}}$ \\ ${ }^{a}$ Department of Medicine, McGill University, Montreal, Que., Canada; ${ }^{b}$ Department of \\ Medicine, University of Toronto, Toronto, Ont., Canada; 'Department of Gastroenterology, \\ McGill University, Montreal, Que., Canada
}

\section{Keywords}

Hepatocellular carcinoma $\cdot$ Crohn's disease $\cdot$ Azathioprine $\cdot$ Spontaneous regression

\begin{abstract}
Hepatocellular carcinoma rarely occurs in patients without underlying cirrhosis or liver disease. While inflammatory bowel disease has been linked to certain forms of liver disease, hepatocellular carcinoma is exceedingly rare in these patients. We report the twelfth case of hepatocellular carcinoma in a patient with Crohn's disease. The patient is a 61-year-old with longstanding Crohn's disease who was treated with azathioprine and was found to have elevated liver enzymes and a new $3-\mathrm{cm}$ liver mass on ultrasound. A complete workup for underlying liver disease was unremarkable and liver biopsy revealed hepatocellular carcinoma. The patient underwent a hepatic resection, and there is no evidence of recurrence at the 11month follow-up. The resection specimen showed no evidence of cancer despite the initial biopsy revealing hepatocellular carcinoma. This case represents the third biopsy-proven complete spontaneous regression of hepatocellular carcinoma. Although large studies have failed to show a definite link between azathioprine and hepatocellular carcinoma, the relationship remains concerning given the multiple case reports suggesting a possible association. Clinicians should exercise a high degree of suspicion in patients with Crohn's disease who present with elevated liver enzymes, especially those on azathioprine therapy.
\end{abstract}

(c) 2016 The Author(s) 
Heron et al.: Resected Hepatocellular Carcinoma in a Patient with Crohn's Disease on Azathioprine

Published by S. Karger AG, Basel

\section{Introduction}

Hepatocellular carcinoma (HCC) is the most common form of primary liver cancer. It is associated with a high mortality rate and its incidence continues to rise [1]. HCC primarily affects patients with underlying liver cirrhosis and those with chronic hepatitis B. An exception to this is fibrolamellar carcinoma, a variation of HCC that affects young individuals without cirrhosis or viral hepatitis [2]. HCC may be suspected in the context of elevated liver enzymes or decompensated cirrhosis. HCC may also be detected on routine surveillance of cirrhotic patients or patients with hepatitis B using alpha-fetoprotein and abdominal imaging. Imaging modalities such as CT and MRI can diagnose HCC with high accuracy; however, a biopsy of the lesion in the liver provides definitive diagnosis.

Inflammatory bowel disease, though associated with certain hepatobiliary conditions including steatosis, drug-induced hepatitis, cholelithiasis, primary sclerosing cholangitis and portal vein thrombosis [3], as well as with certain malignancies such as lymphoma and colon cancer, has never been directly associated with HCC. Over the past few years, however, a number of cases have emerged in the literature reporting HCC in patients with Crohn's disease (CD) in the absence of cirrhosis [4, 5], particularly in those treated with azathioprine [5]. Though azathioprine, which is commonly used in the treatment of $C D$, has never been conclusively linked to HCC, adverse events attributed to this immunosuppressant agent include hepatotoxicity and increased incidence of lymphoma.

This is the twelfth case of HCC in a patient with CD, and the tenth case amongst CD patients on azathioprine. In this report, we review the literature on HCC in CD and discuss the possible role of azathioprine in the development of HCC in these patients. We also address the phenomenon of spontaneous regression of HCC, which has been defined as the partial or total disappearance of a tumor which cannot be explained by the initiation of treatment [6].

\section{Case Presentation}

A 61-year-old Caucasian woman with a 30-year history of CD was found to have a new liver lesion on ultrasound. Her past medical history includes type 2 diabetes treated with oral hypoglycemics (metformin $500 \mathrm{mg}$ b.i.d., sitagliptin $50 \mathrm{mg}$ b.i.d.), dyslipidemia, and nephrolithiasis. Her family history is remarkable for hemochromatosis in her father. She had previously been a light smoker of less than 10 cigarettes per day but quit 10 years ago. She has no history of alcohol or illicit drug use.

At initial diagnosis of $\mathrm{CD}$, she had been well controlled on mesalamine $2 \mathrm{~g}$ b.i.d. Subsequently, between 1985 and 1987 she developed multiple exacerbations including fistulas and abscesses whereby she ultimately required six bowel resections over the next 12 years. During that time she was treated intermittently with corticosteroids, ciprofloxacin $500 \mathrm{mg}$ b.i.d., and metronidazole $500 \mathrm{mg}$ b.i.d.

In April 2001, she developed a recto-vaginal fistula. After failing to respond to antibiotics and probiotics (VSL\#3, 4 packets daily initially, then 2 packets daily), she was started on infliximab $5 \mathrm{mg} / \mathrm{kg}$ infusions. She was well until March 2003, when she developed severe joint pains and recurrence of her fistula. This new fistula responded well to ciprofloxacin and metronidazole, and in October of 2003, azathioprine $2.5 \mathrm{mg} / \mathrm{kg} /$ day was added to her regi- 
men. In 2005, due to a perceived drug reaction, infliximab was stopped. For the past 10 years, she has remained clinically stable on azathioprine alone.

In January 2013, routine blood work revealed a mild asymptomatic rise in her liver enzymes (table 1). Subsequent investigations yielded negative hepatitis A, B and C serologies. Ceruloplasmin, immunoglobulins, lipid profile, and anti-transglutaminase antibody were normal. Serum ferritin ranged between 524 and $710 \mu \mathrm{g} / \mathrm{l}$ (normal 15-300), while iron saturation was normal, ranging from 0.30 to 0.49 during the same period. Her complete blood count and CRP were unremarkable, while the serum alpha-fetoprotein was mildly elevated at $6.6 \mu \mathrm{g} / \mathrm{l}$ (normal 0.0-6.0) as was CA $19-9$ at $130 \mathrm{kU} / \mathrm{l}$ (normal 0-40). In January 2013, azathioprine metabolite monitoring revealed elevated 6-MMP and sub-therapeutic 6-TG levels, while 6-MP levels were undetectable (table 1). In April 2014, when she presented with the liver mass, 6-MMP levels remained high at 12,111, while 6-TG and 6MP were 151 and 35, respectively. The azathioprine dosing was never changed despite increased 6-MMP because 6-TG therapeutic levels were low.

In October 2013, an abdominal ultrasound was performed and revealed no evidence of cirrhosis, focal lesions or fatty infiltrations. Another abdominal ultrasound was repeated in April 2014 due to persistently elevated liver enzymes. At this time, a $2.4 \times 2.6 \times 1.8 \mathrm{~cm}$ hypoechoic area was identified in segment $6 / 7$ of the liver, demonstrating internal septations but no internal vascularity. The lesion was better characterized on an abdominal CT scan with a diameter of $2.9 \mathrm{~cm}$ in segment $6 / 7$ of the liver (fig. 1). This lesion was not present on a previous CT from 2007.

An abdominal MRI confirmed a 3-cm lesion in segment 7, hypointense on T1 and T2 non-fat sat and fat sat acquisitions. The lesion showed arterial enhancement and an enhancing capsule on delayed acquisition. A liver biopsy was performed which showed a welldifferentiated HCC. Histology revealed immunostaining positive for HepPar and CD10 with an absence of staining for CK7 and CK20 (fig. 2). Two expert gastrointestinal pathologists confirmed the diagnosis of HCC on this biopsy. Biopsies from the non-neoplastic liver showed approximately $30 \%$ macrovesicular steatosis without any steatohepatitis or fibrosis, and minimal iron overload (grade $0-1 / 4$; fig. 3 ).

In January 2015, the patient underwent a hepatic resection of the tumor with an uncomplicated postoperative course. Interestingly, the surgical pathology did not reveal any malignant cells. The pathologist speculated that the tumor may have infarcted after biopsy. Notably, azathioprine treatment had been stopped 1 week prior to surgery. Postoperatively, the patient has done well and has no evidence of recurrence at 11 months of follow-up. An abdominal CT scan 5 months after resection shows removal of the liver mass without any evidence of recurrence.

\section{Discussion}

This report represents only the twelfth case of HCC in a patient with CD [4, 5]. Azathioprine therapy has been reported in 9 of the previous 11 cases and has been proposed as a potential trigger in the occurrence of HCC [5]. It is important to note that azathioprine has never been directly linked to the development of HCC in several large-scale studies $[7,8]$. Certainly, one interesting hypothesis to explain a potential association is that azathioprine impairs the immune system's ability to correct dysplasia that can occur in the inflammatory environment created by CD. The known hepatotoxicity of azathioprine as well as its association with malignancies such as lymphoma [9] lends support to this theory. In our case, the 


\section{Case Reports in Gastroenterology}

Case Rep Gastroenterol 2016;10:50-56

(c) 2016 The Author(s). Published by S. Karger AG, Basel www.karger.com/crg

Heron et al.: Resected Hepatocellular Carcinoma in a Patient with Crohn's Disease on Azathioprine

regression of the HCC between the initial biopsy and surgical resection potentially supports this hypothesis as azathioprine was stopped prior to surgery, thereby promoting immune function which may have contributed to the regression of the cancer. Our case is also the first to report azathioprine metabolite levels, which were extremely elevated. It is unclear whether the toxic levels of 6-MMP may have increased the patient's risk of developing HCC. This metabolite in concentrations $>5,700 \mathrm{pmol} / 8 \times 10^{8} \mathrm{RBC}$ has been associated with hepatotoxicity [10], although it has not been reported to cause HCC.

There were no findings of steatohepatitis or cirrhosis to explain the occurrence of HCC, though the patient did have evidence of some macrovesicular steatosis on biopsy. While hemochromatosis is a well-recognized risk factor for HCC, this occurs almost exclusively in the setting of cirrhosis [11]. Some authors have proposed that iron toxicity, even in the absence of cirrhosis, may play a role in the pathogenesis of HCC [11]. Nevertheless, given the minimal amount of iron overload seen on our patient's biopsy, this is unlikely to have played a role in the development of HCC.

Although the biopsy of the liver mass showed HCC, the surgical specimen did not reveal any neoplasia. This is only the third reported case of biopsy-proven HCC with complete histologic spontaneous regression [12,13], though cases of partial or complete regression based on diagnostic imaging have also been reported. Spontaneous regression of cancer is a rare phenomenon that has been a source of discussion for over 50 years [6]. According to a recent systematic review, the rate of partial spontaneous regression of HCC (defined as radiologic decrease of $>50 \%$ in diameter) was $0.406 \%$, and a spontaneous decrease in diameter $>25 \%$ occurred at a rate of $2.320 \%$ [14]. The precise mechanism of regression remains unclear. Tumor hypoxia by interruption of blood supply to the tumor and systemic inflammatory response via cytokine activation are two commonly proposed mechanisms to explain this phenomenon. Other theories include withdrawal of etiologic agents such as alcohol, as well as possible immunologic pathways [15]. In our case, the withdrawal of azathioprine may have played a role both by elimination of a causal agent and also possibly by promoting a heightened immune response. Other possibilities include the liver biopsy itself since it is well established that operative trauma, including biopsy, has been linked to spontaneous regression [6].

\section{Conclusion}

If discovered early, HCC in the setting of CD may be curable. The pathogenesis of HCC in such patients remains largely unknown, as does the role of azathioprine despite being linked in various case reports. Future research may uncover further risk factors in the development of HCC in patients with CD. Another important question is whether or not immediate azathioprine cessation is beneficial in the treatment of HCC in such patients, and whether closer monitoring of drug levels can prevent potential complications including malignancy or infection. While blood work including liver enzymes is routine in the management of patients with $C D$, regular imaging is not part of standard practice. As such, early imaging should be strongly considered in patients with CD who present with abnormal liver enzymes or symptoms consistent with liver disease. Heightened awareness may be indicated in patients treated with azathioprine or other immunosuppressants, especially in patients with elevated drug levels. 
Heron et al.: Resected Hepatocellular Carcinoma in a Patient with Crohn's Disease on Azathioprine

\section{Statement of Ethics}

The patient provided informed consent for publication of this case report. No identifying information or images have been included in this manuscript.

\section{Disclosure Statement}

All authors declare no conflicts of interests in the publication of this paper.

\section{References}

1 El-Serag HB, Mason AC: Rising incidence of hepatocellular carcinoma in the United States. N Engl J Med 1999;340:745-750.

2 El-Serag HB, Davila JA: Is fibrolamellar carcinoma different from hepatocellular carcinoma? A US population-based study. Hepatology 2004;39:798-803.

3 Rojas-Feria M, Castro M, Suarez E, Ampuero J, Romero-Gomez M: Hepatobiliary manifestations in inflammatory bowel disease: the gut, the drugs and the liver. World J Gastroenterol 2013;19:7327 7340.

4 Ishida M, Naka S, Shiomi H, Tsujikawa T, Andoh A, Nakahara T, et al: Hepatocellular carcinoma occurring in a Crohn's disease patient, World J Gastroenterol 2010;16:3215-3218.

-5 Fortinsky KJ, Alali A, Jeejeebhoy K, Fischer S, Sherman M, Fung S: Metastatic hepatocellular carcinoma in a patient with Crohn's disease treated with azathioprine and infliximab: a case report and literature review. Case Rep Gastrointest Med 2014;2014:340836.

6 Cole WH: Efforts to explain spontaneous regression of cancer. J Surg Oncol 1981;17:201-209.

7 Armstrong RG, West J, Card TR: Risk of cancer in inflammatory bowel disease treated with azathioprine: a UK population-based case-control study. Am J Gastroenterol 2010;105:1604-1609.

8 Pasternak B, Svanstrom H, Schmiegelow K, Jess T, Haviid A: Use of azathioprine and the risk of cancer in inflammatory bowel disease. Am J Epidemiol 2013;177:1296-1305.

-9 Subramaniam K, Yeung D, Grimpen F, Joseph J, Fay K, Buckland M, et al: Hepatosplenic T-cell lymphoma, immunosuppressive agents and biologicals: what are the risks? Intern Med J 2014;44:287290.

10 Dubinsky MC, Lamothe S, Yang HY, Targan SR, Sinnett D, Théorêt Y, et al: Pharmacogenomics and metabolite measurement for 6-mercaptopurine therapy in inflammatory bowel disease. Gastroenterology 2000;118:705-713.

-11 Kowdley KV: Iron, hemochromatosis, and hepatocellular carcinoma. Gastroenterology 2004;127(5 suppl 1):S79-S86.

12 Kaczynski J, Hansson G, Remotti H, Wallerstedt S: Spontaneous regression of hepatocellular carcinoma. Histopathology 1998;32:147-150.

-13 Storey RE, Huerta AL, Khan A, Laber DA: Spontaneous complete regression of hepatocellular carcinoma. Med Oncol 2011;28:948-950.

14 Oquiñena S, Guillen-Grima F, Iñarrairaegui M, Zozaya JM, Sangro B: Spontaneous regression of hepatocellular carcinoma: a systematic review. Eur J Gastroenterol Hepatol 2009;21:254-257.

15 Huz JI, Melis M, and Sarpel U: Spontaneous regression of hepatocellular carcinoma is most often associated with tumour hypoxia or a systemic inflammatory response. HPB (Oxford) 2012;14:500-505 


\section{Case Reports in Gastroenterology

\begin{tabular}{l|l}
\hline Case Rep Gastroenterol 2016;10:50-56 \\
\hline $10.1159 / 000444012$ & $\begin{array}{l}\text { c) 2016 The Author(s). Published by S. Karger AG, Basel } \\
\text { www.karger.com/crg }\end{array}$ \\
\hline
\end{tabular} www.karger.com/crg \\ Heron et al.: Resected Hepatocellular Carcinoma in a Patient with Crohn's Disease on Azathioprine}

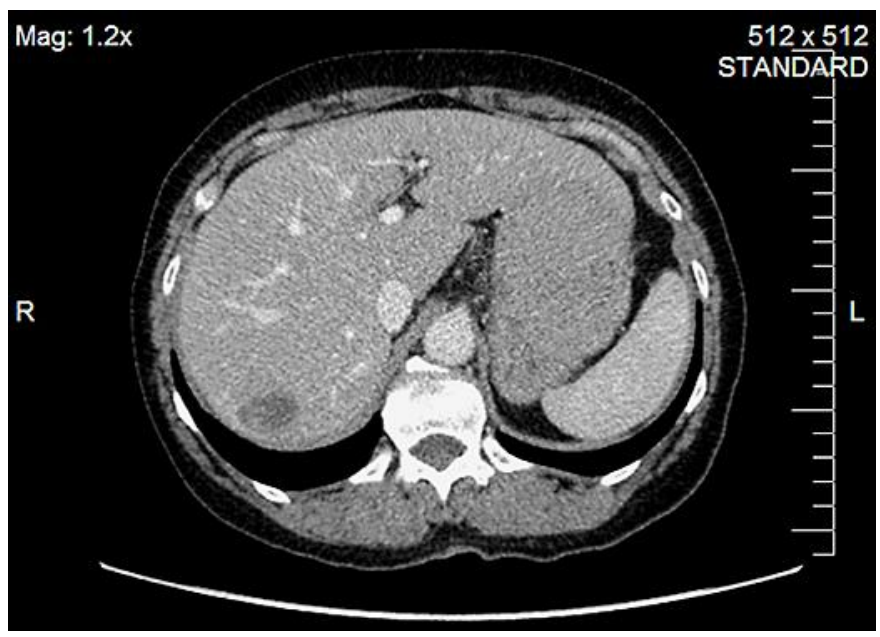

Fig. 1. A liver mass measuring $2.9 \mathrm{~cm}$ in segment $6 / 7$ of the liver is shown on abdominal CT scan. The lesion was characterized as hypodense with peripheral rim enhancement and internal septation.

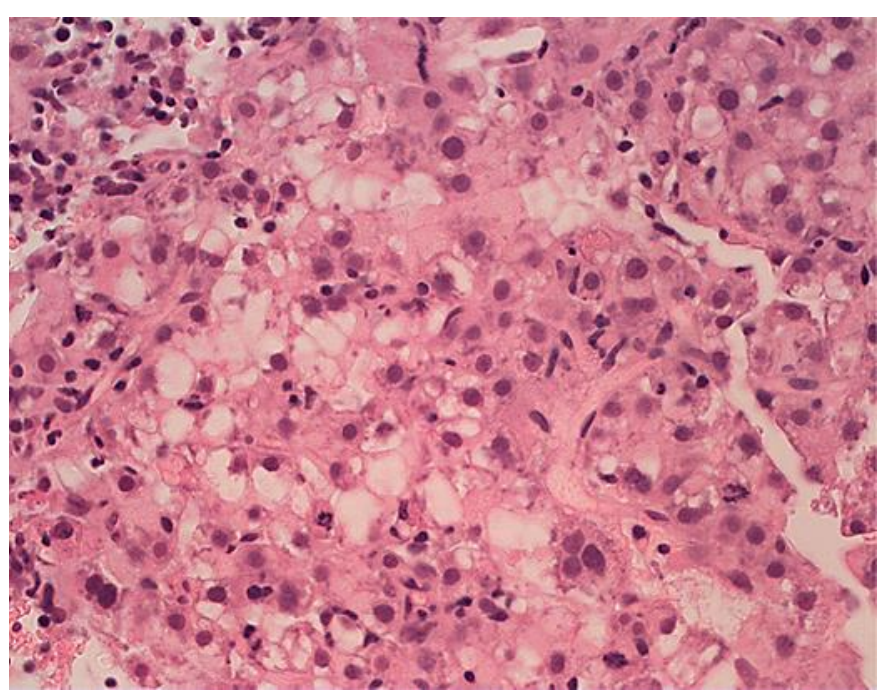

Fig. 2. Biopsy of the liver lesion showed well-differentiated HCC. Magnification $\times 200$. 


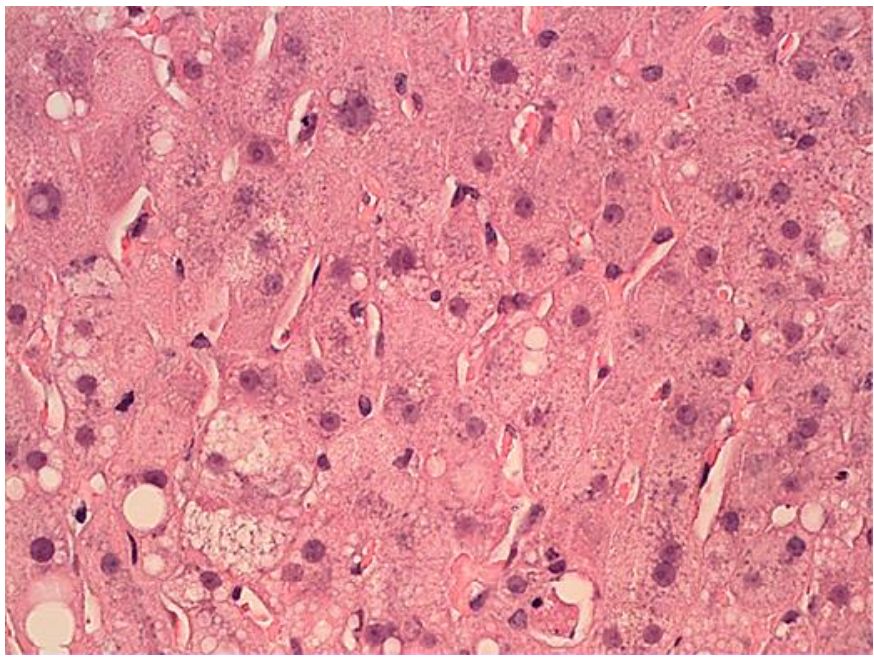

Fig. 3. Non-neoplastic liver biopsy showed 30\% macrovesicular steatosis and minimal iron overload (grade $0-1 / 4$ ), but no steatohepatitis and no fibrosis. Magnification $\times 200$.

Table 1. Laboratory values from January 2013

\begin{tabular}{llc}
\hline Laboratory parameter & Initial value & Reference range \\
\hline Hemoglobin, g/l & 141 & $120-152$ \\
Creatinine, $\mu$ mol/l & 68 & $45-95$ \\
Alanine aminotransferase, IU/l & 56 & $5-40$ \\
Aspartate aminotransferase, IU/l & 71 & $15-55$ \\
Alkaline phosphatase, IU/l & 39 & $35-145$ \\
Total bilirubin, $\mu$ mol/l & 15 & $3-17$ \\
International normalized ratio & 1.0 & $0.9-1.2$ \\
Ferritin, $\mu$ g/l & 605 & $15-300$ \\
Iron saturation & 0.36 & $0.15-0.50$ \\
Alpha fetoprotein, $\mu \mathrm{g} / \mathrm{l}$ & 6.6 & $0.0-6.0$ \\
CA 19-9, kU/l & 120 & $0-40$ \\
6-TGN, pmol/8 $\times 10^{8} \mathrm{RBCs}$ & 124 & $235-450$ \\
6-MP, pmol/8 $\times 10^{8} \mathrm{RBCs}$ & Non-detectable & $\mathrm{NA}$ \\
6-MMP, pmol/8 $\times 10^{8} \mathrm{RBCs}$ & 19,431 & $<5,700$ \\
\hline
\end{tabular}

